\title{
MONITORAMENTO TECNOLÓGICO PARA GENES DE INTERESSE PARA A COMPOSIÇÃO DA CARCAÇA EM FRANGO DE CORTE
}

\author{
Thaisy Sluszz $^{1 *}$; Marcio Gilberto Saatkamp ${ }^{1}$; Claudia Antunez Arrieche ${ }^{1}$; Adriana Mercia Guaratini \\ Ibelli $^{1}$; Luciana Harumi Morimoto Figueiredo ${ }^{2}$ \\ ${ }^{1}$ Embrapa Suínos e Aves, BR 153, km 110, Caixa Postal 21, 89700-000, Concórdia/SC \\ (thaisy.sluszz@embrapa.br). \\ ${ }^{2}$ Secretaria de Negócios da Embrapa, PqEB Av. W3 norte (final), Plano Piloto, CEP 70770-901. \\ Brasília/DF.
}

\section{RESUMO}

O melhoramento avícola apresenta constantes desenvolvimentos científicos e tecnológicos, integração de mercados e acirrada competição econômica. Em segmentos desta natureza, as informações tornam-se cada vez mais necessárias para auxiliar as estratégias de PD\&I. Assim, este estudo utiliza informações tecnológicas (patentárias, científicas e de mercado) para o monitoramento da área biotecnológica aplicada ao melhoramento de frangos de corte, especificamente genes para composição de carcaça. De acordo com os resultados, a utilização de genômica para seleção de frangos de corte via genes de composição para carcaça é um tema ainda incipiente e recente, sendo a China e os Estados Unidos os países com maior contribuição. Universidades e institutos de P\&D são as organizações que apresentam mais trabalhos na área e as empresas privadas tem programas de melhoramento não divulgados. As técnicas de biotecnologia têm sido incorporadas aos programas de melhoramento lentamente e possivelmente nos próximos anos seja utilizada em larga escala.

Palavras Chave: avicultura; melhoramento animal; prospecção tecnológica; estratégia.

\begin{abstract}
The poultry breeding presents constant scientific and technological improvements, market integration and hard economic competition. In such segments, the information becomes increasingly necessary to assist the RD\&I strategies. This study uses technological information (patenting, scientific and market) for monitoring the biotechnology area applied to the broiler breeding, specifically genes for carcass composition. The results show that the use of genomic selection in broilers with genes for carcass composition is a new and recent topic, and China and the United States have the highest contribution rates. Universities and R\&D organizations have most of the studies in this area. The private companies breeding programs are kept secret as a competitive strategy. The biotechnology techniques have been incorporated into breeding programs slowly and possibly will be used on a large scale over the next few years.
\end{abstract}

Key words: poultry; animal breeding; technological foresight; strategy.

Área tecnológica: Biotecnologia; Alimentos.

Cadernos de Prospecção - ISSN 1983-1358 (print) 2317-0026 (online), 2013, vol.6, n.1, p.7-19.

D.O.I.: http://dx.doi.org/10.9771/S.CPROSP.2013.001.002 


\section{INTRODUÇÃO}

A evolução da avicultura representa o sucesso da inovação em busca da eficiência da produção animal. As melhorias dos índices zootécnicos de frangos de corte tiveram contribuição da nutrição, ambiência, sanidade, mas principalmente do melhoramento genético, que permitiu o aumento do volume e da eficiência de produção das linhagens de aves (ALBERS et al., 1998).

O método de seleção genética tradicional é realizado pelo fenótipo, sem o conhecimento do número e do efeito dos genes que atuam nas características de interesse (LEDUR et al., 2003). Mesmo assim, as taxas de ganho genético que foram e ainda estão sendo obtidas em programas de melhoramento, demonstram o sucesso do uso da genética quantitativa na seleção de aves (DEKKERS, 1999).

A partir de 2000, com o desenvolvimento mais avançado da biotecnologia, estão sendo disponibilizadas ferramentas para elucidar o controle genético de características quantitativas complexas, como é o caso das características de produção. Dentre essas ferramentas incluem-se a identificação de regiões cromossômicas associadas a QTLs (loci que afetam características quantitativas) e mutações funcionais (causais). A genética molecular pode ser utilizada como complemento aos métodos tradicionalmente empregados, por meio da seleção assistida por marcadores, para melhorar a eficiência dos programas de melhoramento (LEDUR et al., 2003). Assim, algumas limitações da seleção baseada no fenótipo poderão ser parcialmente eliminadas com o uso da informação molecular, possibilitando a seleção diretamente pelo genótipo (DNA), resultando em uma seleção mais acurada ou precoce ou ainda de mais baixo custo (DEKKERS; HOSPITAL, 2002), dependendo da característica em questão (LEDUR et al., 2003).

Pensando nas inovações possíveis para o setor, a Embrapa Suínos e Aves, em parceria com diferentes instituições, como a Escola Superior de Agricultura Luiz de Queiroz (ESALQ/USP), Universidade Estadual de Londrina (UEL) e Universidade Estadual de São Paulo (UNESP), desenvolve estudos com o objetivo de mapear QTLs para várias características de importância econômica em aves, nas condições brasileiras. Um dos temas da pesquisa é a prospecção de genes de interesse para composição de carcaças em frangos de corte, importante variável para a seleção de linhagens mais produtivas.

O melhoramento de aves é um tema em constante e rápida mutação, marcado por constantes desenvolvimentos científicos e tecnológicos, integração de mercados e acirrada competição econômica, onde as organizações precisam de informações confiáveis e precisas para tomada de decisão e elaboração de estratégias para ampliar sua competitividade e sustentabilidade negocial.

Dessa forma, o monitoramento tecnológico se torna importante ferramenta, pois permite acompanhar, em âmbito mundial, os avanços tecnológicos no tema de interesse, além de identificar tendências futuras e analisar suas consequências para tomada de decisões, seja em aspectos de pesquisa, desenvolvimento e inovação, administração e finanças ou negócios.

Assim, visando auxiliar as pesquisas e trazer informações para subsidiar programas de transferência de tecnologia da Embrapa Suínos e Aves, este trabalho objetivou realizar o monitoramento tecnológico para prospecção de tecnologias e instituições que tenham atuação relacionada à pesquisa de genes de interesse para a composição da carcaça em frango de corte. 


\section{DESCRIÇÃO DA TECNOLOGIA}

Os pilares do desenvolvimento avícola estão sustentados na utilização de genética avançada, a qual deve buscar aves compatíveis com as exigências altamente competitivas dos mercados produtivo, industrial e consumidor (CAMPOS et al., 1999). Neste contexto, segundo Gaya, Mourão e Ferraz (2006), cada vez mais a indústria avícola definirá o produto a ser utilizado com base nos benefícios que este proporcionará em toda a cadeia, da reprodução ao processamento pós-abate. Como resultado deste processo, o estabelecimento de critérios de seleção adequados e eficientes torna-se ao mesmo tempo o principal objetivo e um grande obstáculo ao desenvolvimento de programas de melhoramento genético de aves (GAYA et al., 2006).

Num programa de melhoramento genético, são fundamentais as estimativas dos parâmetros genéticos dos critérios de seleção utilizados. Segundo Campos e Pereira (1999), a quantificação da variação genética das características e as associações genéticas entre diferentes características permitem estabelecer estratégias de melhoramento animal e o monitoramento da variabilidade genética dos indivíduos da linhagem utilizada para várias características.

As características de desempenho tendem a ser fortemente correlacionadas com as características de carcaça, segundo Campos e Pereira (1999). De acordo com a literatura sobre o tema, parece existir forte associação genética entre o peso vivo e as características de carcaça. Estas informações reforçam as afirmações de Chambers (1990), de que a seleção para peso vivo e peso de peito podem ser capazes de aumentar os rendimentos de carcaça em frangos de corte. Da mesma forma, as estimativas de correlação genética entre peso vivo e peso eviscerado (WANG et al., 1991; ARGENTÃO et al., 2002; GAYA, 2003), com peso de peito indiretamente correlacionado, são indicadores de que esta seleção pode ser capaz de incrementar o rendimento de carcaça.

Desta forma, a seleção de genes de interesse para composição de carcaça relacionados a peso de peito é fundamental em um programa de melhoramento genético que vise uma maior produtividade e é sobre este tema que foi realizado este monitoramento tecnológico.

\section{METODOLOGIA}

Para este estudo, foi utilizado o monitoramento tecnológico como metodologia de prospecção. O uso do monitoramento tecnológico apresenta algumas vantagens, como: auxilio na previsão de cenários para tecnologias de interesse; antecipação e entendimento do percurso das mudanças em um tema; subsidia e orienta o processo de tomada de decisão em ciência, tecnologia e inovação; subsidia decisões relativas ao estabelecimento de prioridades em $\mathrm{P} \& \mathrm{D}$, gestão de risco das inovações tecnológicas e melhoria da competitividade tecnológica de produtos e processos.

O monitoramento tecnológico do presente trabalho envolveu seis atividades, que incluem a elaboração da estratégia de busca, a busca em bancos de patentes e de publicações científicas, a aquisição de informações relativas ao mercado das tecnologias encontradas nas buscas dos documentos, a sistematização destes dados e sua análise final.

Os bancos utilizados para buscas de publicações científicas foram Web of Science e Scopus, por serem multidisciplinares e possuírem amplo escopo, ampliando a possibilidade de encontrar documentos relevantes ao tema. 
Para os documentos de patente, a Derwent Innovations Index (DII) foi a base utilizada, pois apresenta algumas vantagens em relação às outras bases de dados de patentes disponíveis gratuitamente. Uma das vantagens é que todo documento de patente é trabalhado por especialistas que publicam na base as informações mais relevantes do documento. A base engloba ainda documentos de diversos países tendo, portanto, escopo global.

As informações de mercados foram obtidas por meio de buscas na internet e mídias especializadas, principalmente nos sites das empresas privadas mais relevantes do setor de melhoramento de frangos de corte.

A estratégia de busca, específica relacionada a genes para a composição da carcaça em frangos de corte, foi elaborada por meio da escolha das palavras-chave e classificação internacional correspondente, de acordo com o objetivo de cada busca: artigos científicos e documentos de patentes, sendo especificada da seguinte forma:

- Artigos científicos:

Topic $=($ broiler or poultry or chicken or gallus $)$ AND Topic $=($ snp or marker or polymorphism or mutation $)$ AND Topic $=($ association or effect or influence $)$ AND Topic $=($ breast $)$ AND NOT

Topic $=$ (human).

- Documentos de patentes:

IPC Code ${ }^{1}=\left(\mathrm{C} 07 \mathrm{H}-021 *\right.$ or $\mathrm{C} 07 \mathrm{~K}^{*}$ or $\left.\mathrm{C} 12 \mathrm{~N}-015^{*}\right)$ AND Topic $=($ chicken or broiler or poultry $)$ AND Topic $=($ carcass or breast $)$ NOT Topic $=($ human $)$.

O período de recuperação dos dados nas bases teve como limite o dia 30 de setembro de 2012 e foi realizada pelos analistas da Embrapa Suínos e Aves, com a colaboração da equipe técnica de melhoramento de aves da Unidade. A colaboração dos especialistas se deu na elaboração das palavras-chave para estratégia de busca e na validação dos resultados.

- Documentos de mercado:

(market or trade, commerce) AND (broiler or poultry or chicken or gallus) AND (snp or marker or polymorphism or mutation)

Cabe ressaltar, que a adequada análise das informações tecnológicas demanda múltiplas atividades para monitorar e interpretar corretamente a dinâmica do ambiente. Neste sentido, o presente estudo trabalhou na aplicação da ferramenta utilizando informações tecnológicas (patentárias, científicas e de mercado) para o monitoramento tecnológico da área de biotecnologia aplicada ao melhoramento de frangos de corte, especificamente genes para composição de carcaça.

Após o tratamento dos dados em planilhas Excel, foi elaborado um relatório que foi validado pela equipe técnica do assunto e divulgado internamente para subsidiar o processo de pesquisa, desenvolvimento e inovação (PD\&I) da Embrapa Suínos e Aves e demais parceiros.

\footnotetext{
${ }^{1}$ IPC code: Classificação Internacional de Patentes utilizada na busca
} 


\section{RESULTADOS E DISCUSSÃO}

Foram encontrados 176 documentos nas bases Web of Science e Scopus. Entretanto, apenas 64 documentos apresentaram relevância no tema foco deste estudo e apenas estes foram utilizados para as análises.

De acordo com os dados, considerando o país de origem da instituição que publicou o trabalho, o país com maior número de publicações é a China (51\%), seguido de França (14\%) e Estados Unidos (9\%), conforme Figura 1. O Brasil aparece com apenas uma publicação, sendo este resultado da linha de pesquisa em melhoramento de frangos de corte conduzido pela Embrapa Suínos e Aves, em parceria com Escola Superior de Agricultura Luiz de Queiroz (ESALQ/USP) e a Universidade Estadual de São Paulo (UNESP). O Brasil não apresenta, ainda, expressão em termos de quantidade de publicação a respeito do tema, visto que as pesquisas na área de melhoramento genético de frangos de corte é um tema recente e que necessita de alto investimento, tanto em recursos humanos quanto financeiros. Além disso, os programas de melhoramento são liderados por grandes empresas multinacionais, cujas pesquisas são mantidas em sigilo por estratégia competitiva.

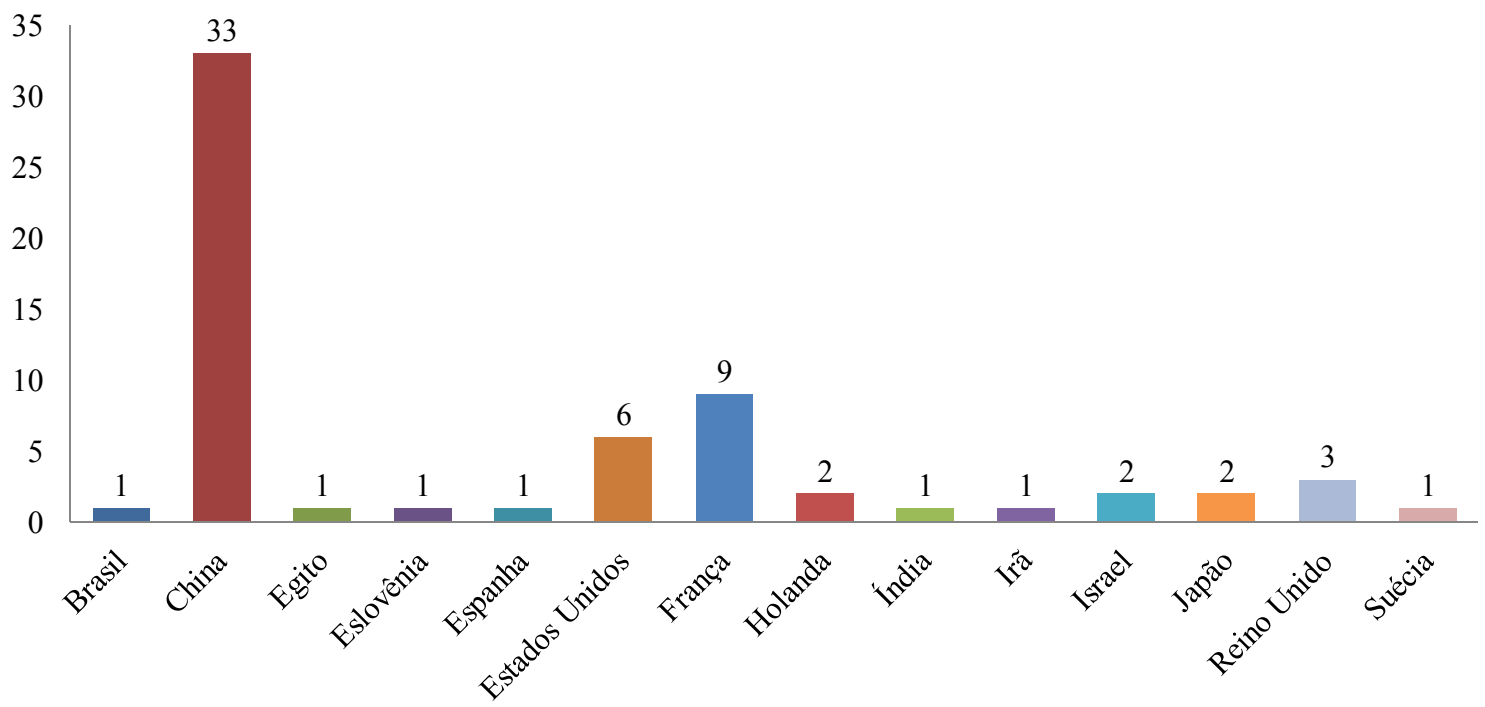

Figura 1: Contribuição dos países, em publicações relativas ao tema de genes para composição de carcaça de frangos de corte, de acordo com o resultado das buscas nos bancos Web of Science e Scopus. Fonte: Autoria própria, 2012.

As publicações relevantes sobre o tema se deram a partir de 1999, tendo uma concentração em 2007, conforme o Figura 2, indicando que o tema vem ganhando relevância no decorrer dos anos, pelo aumento da aplicabilidade da tecnologia nos programas de melhoramento. 


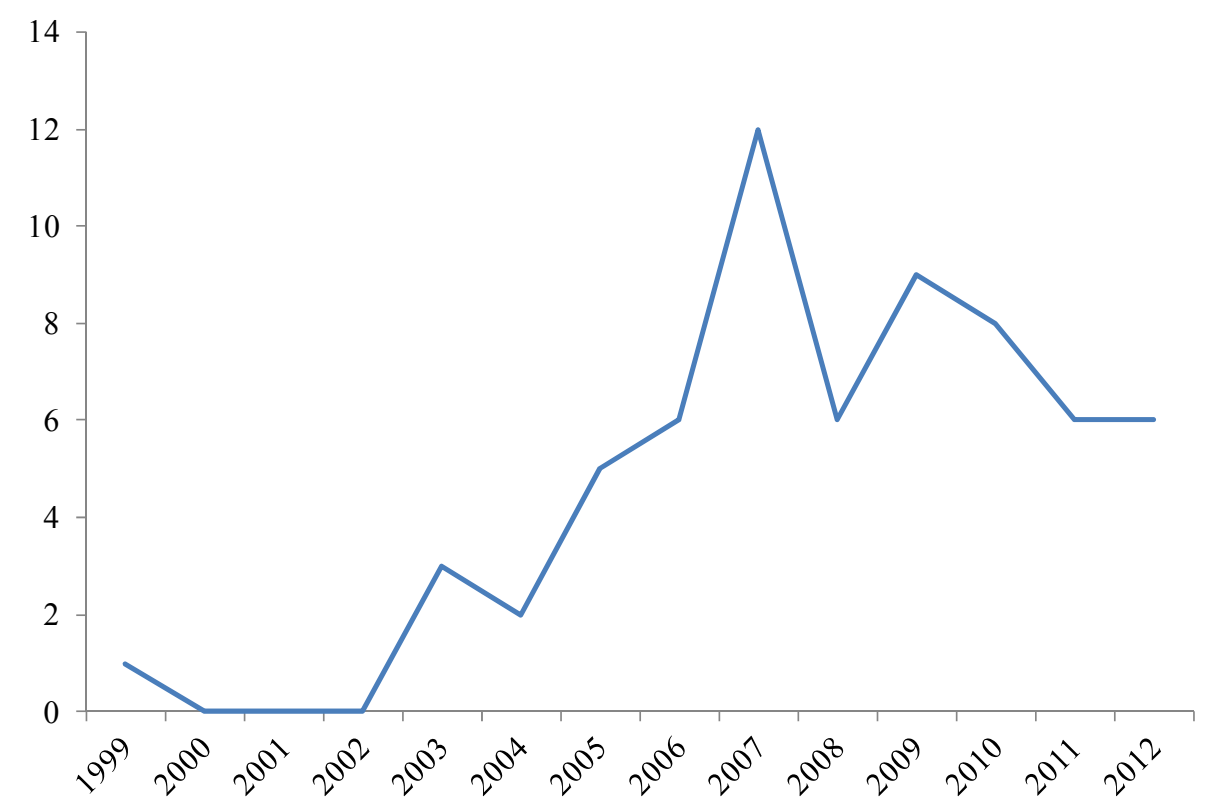

Figura 2: Número de publicações científicas por ano a respeito de genes de interesse para a composição da carcaça em frango de corte, resultado da busca realizada conforme estratégia definida. Fonte: Autoria própria, 2012.

O artigo mais relevante foi publicado em 1999, sendo um marco nos estudos de biotecnologias em frango de corte com 60 citações. Intitulado "Whole genome scan in chickens for quantitative trait loci affecting carcass traits" foi publicado na Poultry Science, pelos autores Van Kaam J.B. et al, e é resultado de estudos do Animal Breeding and Genetics Group, da Wageningen Agricultural University (Holanda), que descreve um experimento que identificou os cromossomos mais significativos com efeitos sobre rendimento de carcaça e cor da carne.

Os artigos mais citados, de acordo com as bases utilizadas estão listados na Tabela 1. Pode-se observar que universidades e instituições de $\mathrm{P} \& \mathrm{D}$, por citações relacionadas, são os tipos de organizações que apresentam maior contribuição ao tema.

Verifica-se, de acordo com os resultados apresentados, que os artigos mais citados não são dos autores com maior número de publicação, ou seja, Zeng Rong Zhang, Yi Ping Liu, Yong Gang Yao, Xiao Song Jiang, Hua Rui Du e Qing Zhu, de institutos e universidades da China, mas, principalmente, de pesquisadores da Holanda, Estados Unidos e França (Tabela 1). 
Tabela 1: Artigos mais citados de acordo com o resultado da busca nas bases Scopus e Web of Science, a instituição a que pertencem os autores, o ano de publicação, a revista de publicação, o país de origem dos primeiros autores e o número de citações referenciadas nas bases de busca.

\begin{tabular}{|c|c|c|c|c|c|}
\hline Artigo & Instituição & Ano & Periódico & País & Citações \\
\hline $\begin{array}{l}\text { Whole genome scan in chickens for quantitative } \\
\text { trait loci affecting carcass traits }\end{array}$ & $\begin{array}{l}\text { Wageningen } \\
\text { Agricultural } \\
\text { University } \\
\end{array}$ & 1999 & Poultry Science & Holanda & 60 \\
\hline $\begin{array}{c}\text { Chicken quantitative trait loci for growth and } \\
\text { body composition associated with transforming } \\
\text { growth factor- } \beta \text { genes }\end{array}$ & $\begin{array}{l}\text { Iowa State } \\
\text { University }\end{array}$ & 2003 & Poultry Science & $\begin{array}{l}\text { Estados } \\
\text { Unidos }\end{array}$ & 41 \\
\hline $\begin{array}{c}\text { Insulin-like growth factor-I gene polymorphism } \\
\text { associations with growth, body composition, } \\
\text { skeleton integrity, and metabolic traits in } \\
\text { chickens }\end{array}$ & $\begin{array}{l}\text { Iowa State } \\
\text { University }\end{array}$ & 2005 & Poultry Science & $\begin{array}{l}\text { Estados } \\
\text { Unidos }\end{array}$ & 33 \\
\hline $\begin{array}{l}\text { Mapping quantitative trait loci affecting fatness } \\
\text { and breast muscle weight in meat-type chicken } \\
\text { lines divergently selected on abdominal fatness }\end{array}$ & $\begin{array}{c}\text { Institut National de } \\
\text { la Recherche } \\
\text { Agronomique }\end{array}$ & 2006 & $\begin{array}{l}\text { Genetics } \\
\text { Selection } \\
\text { Evolution }\end{array}$ & França & 33 \\
\hline $\begin{array}{l}\text { Quantitative trait loci for meat yield and muscle } \\
\text { distribution in a broiler layer cross }\end{array}$ & $\begin{array}{l}\text { The Roslin } \\
\text { Institute }\end{array}$ & 2004 & $\begin{array}{l}\text { Livestock } \\
\text { Production } \\
\text { Science } \\
\end{array}$ & $\begin{array}{l}\text { Reino } \\
\text { Unido }\end{array}$ & 26 \\
\hline $\begin{array}{c}\text { Single nucleotide polymorphisms of the chicken } \\
\text { insulin-like factor binding protein } 2 \text { gene } \\
\text { associated with chicken growth and carcass } \\
\text { traits }\end{array}$ & $\begin{array}{l}\text { South China } \\
\text { Agricultural } \\
\text { University }\end{array}$ & 2005 & Poultry Science & China & 25 \\
\hline $\begin{array}{l}\text { Genome-wide linkage analysis to identify } \\
\text { chromosomal regions affecting phenotypic traits } \\
\text { in the chicken. II. Body composition }\end{array}$ & $\begin{array}{l}\text { Iowa State } \\
\text { University }\end{array}$ & 2006 & Poultry Science & $\begin{array}{l}\text { Estados } \\
\text { Unidos }\end{array}$ & 24 \\
\hline $\begin{array}{l}\text { Identification of QTL controlling meat quality } \\
\text { traits in an F2 cross between two chicken lines } \\
\text { selected for either low or high growth rate }\end{array}$ & $\begin{array}{c}\text { Institut National de } \\
\text { la Recherche } \\
\text { Agronomique }\end{array}$ & 2007 & BMC Genomics & França & 17 \\
\hline $\begin{array}{c}\text { Polymorphism of growth-correlated genes } \\
\text { associated with fatness and muscle fiber traits in } \\
\text { chickens }\end{array}$ & \begin{tabular}{c|} 
South China \\
Agricultural \\
University
\end{tabular} & 2007 & Poultry Science & China & 15 \\
\hline $\begin{array}{l}\text { QTL for several metabolic traits map to loci } \\
\text { controlling growth and body composition in an } \\
\text { F2 intercross between high- and low-growth } \\
\text { chicken lines }\end{array}$ & $\begin{array}{l}\text { Institut National de } \\
\text { la Recherche } \\
\text { Agronomique }\end{array}$ & 2009 & $\begin{array}{l}\text { Physiol } \\
\text { Genomics }\end{array}$ & França & 15 \\
\hline $\begin{array}{l}\text { Genetical genomics: combining gene expression } \\
\text { with marker genotypes in poultry }\end{array}$ & $\begin{array}{l}\text { The Roslin } \\
\text { Institute }\end{array}$ & 2007 & Poultry Science & $\begin{array}{l}\text { Reino } \\
\text { Unido }\end{array}$ & 13 \\
\hline $\begin{array}{l}\text { QTLs associated with growth traits and } \\
\text { abdominal fat weight and their interactions with } \\
\text { gender and hatch in commercial meat-type } \\
\text { chickens }\end{array}$ & $\begin{array}{c}\text { Hebrew University } \\
\text { of Jerusalem }\end{array}$ & 2006 & Animal Genetics & Israel & 12 \\
\hline $\begin{array}{c}\text { Associations of myostatin gene polymorphisms } \\
\text { with performance and mortality traits in broiler } \\
\text { chickens }\end{array}$ & $\begin{array}{l}\text { Iowa State } \\
\text { University }\end{array}$ & 2007 & $\begin{array}{l}\text { Genetics } \\
\text { Selection } \\
\text { Evolution }\end{array}$ & $\begin{array}{l}\text { Estados } \\
\text { Unidos }\end{array}$ & 11 \\
\hline $\begin{array}{l}\text { Genetic mapping of quantitative trait loci } \\
\text { affecting growth and carcass traits in F } 2 \\
\text { intercross chickens }\end{array}$ & $\begin{array}{c}\text { National Livestock } \\
\text { Breeding Center }\end{array}$ & 2009 & Poultry Science & Japão & 10 \\
\hline
\end{tabular}

Fonte: Autoria própria, 2012. 
Quanto à contribuição das instituições para as publicações relevantes a respeito de genes para composição da carcaça em frango de corte, considerando inclusive os coautores dos principais trabalhos selecionados, podemos verificar que as universidades apresentam um maior número de pesquisadores envolvidos neste tema (57\%), seguidos de instituições de pesquisa e desenvolvimento (P\&D) (38\%), sendo que apenas $5 \%$ dos resultados tiveram contribuição da iniciativa privada, conforme Figura 3.

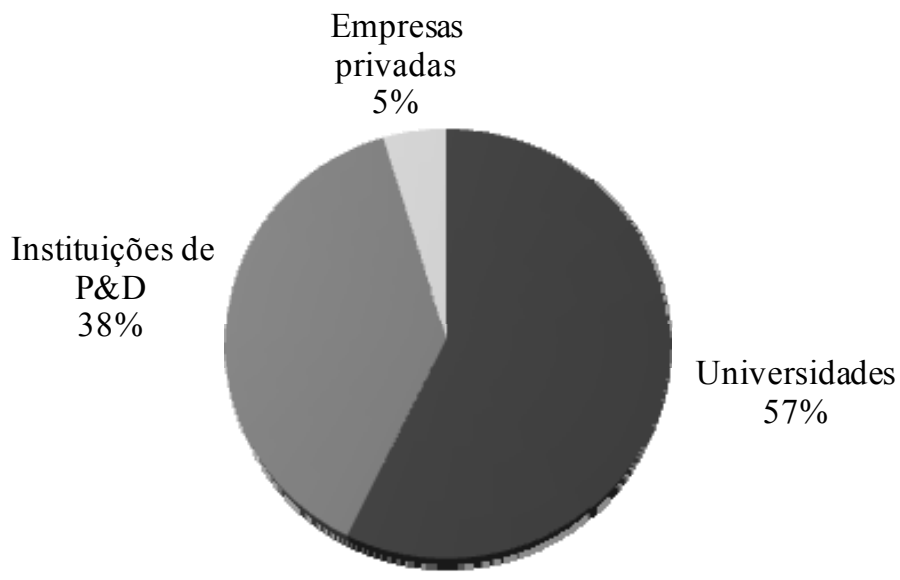

Figura 3: Contribuição por tipo de instituição de acordo com o número de publicações relevantes no tema de genes para composição de carcaças de frango de corte. Fonte: Autoria própria, 2012.

A contribuição da iniciativa privada no melhoramento genético de frangos de cortes é bem mais expressiva do que foi identificado nos resultados. Isto se deve ao fato das empresas do setor manter sigilo dos seus resultados, por estratégia empresarial, devido à alta concorrência deste segmento.

Quando consideramos documentos de patentes, o resultado da busca retornou 33 documentos, sendo que apenas sete foram relevantes ao tema de estudo. Deve-se ressaltar que muitos documentos ainda se encontram em período de sigilo, devido a sua data de depósito recente, e, por esta razão, não foram detectados pela busca do presente trabalho.

Um depósito foi realizado em 1998 e os demais a partir de 2008, corroborando com os resultados obtidos nas publicações sobre o tema, que indicam que este é recente em sua aplicação no melhoramento genético de frangos de corte e requer investimento e tempo para que resultados aplicáveis sejam obtidos. A recuperação dos dados está apresentada na Tabela 2. 
Tabela 2: Documentos patentários encontrados na base Derwent, de acordo com estratégica de busca elaborada, considerando número da patente, título, instituição depositante, inventores e data । depósito.

\begin{tabular}{|c|c|c|c|c|}
\hline Número Patente & Título & Instituição & Inventor & $\begin{array}{l}\text { Data de } \\
\text { Depósito }\end{array}$ \\
\hline CN102250889-A & $\begin{array}{c}\text { New single } \\
\text { nucleotide } \\
\text { polymorphism } \\
\text { (SNP) marker } \\
\text { related to chicken } \\
\text { carcass characteristic } \\
\text { comprises SNP1-10, } \\
\text { useful for detecting } \\
\text { chicken group } \\
\text { carcass } \\
\text { characteristics and } \\
\text { breeding chicken }\end{array}$ & $\begin{array}{l}\text { Sichuan } \\
\text { Agriculture } \\
\text { University }\end{array}$ & $\begin{array}{l}\text { HU Y, LAN D, } \\
\text { LIU Y, et. al }\end{array}$ & 14 Jul 2011 \\
\hline CN102031257-A & $\begin{array}{l}\text { New molecular } \\
\text { marker useful for } \\
\text { selecting the chicken } \\
\text { carcass property, } \\
\text { comprising a single } \\
\text { base mutation } \\
\text { outside of fat mass } \\
\text { and obesity- } \\
\text { associated gene }\end{array}$ & $\begin{array}{l}\text { South China } \\
\text { Agricultural } \\
\text { University }\end{array}$ & $\begin{array}{c}\text { ZHANG X, NIE } \\
\text { Q, JIA X }\end{array}$ & 17 Sep 2010 \\
\hline CN102021174-A & $\begin{array}{l}\text { New chicken fat } \\
\text { candidate Lpin2 } \\
\text { gene sequence, } \\
\text { useful for detecting } \\
\text { single nucleotide } \\
\text { polymorphisms and } \\
\text { determining } \\
\text { functional gene } \\
\text { influencing the } \\
\text { growth of chicken, } \\
\text { the carcass traits, } \\
\text { and the specific } \\
\text { mutation site }\end{array}$ & $\begin{array}{l}\text { Huang Y. } \\
\text { (individual) }\end{array}$ & $\begin{array}{l}\text { WANG Y, KANG } \\
\text { X, HAN R, et. al }\end{array}$ & 27 Aug 2010 \\
\hline
\end{tabular}


Tabela 2: Documentos patentários encontrados na base Derwent, de acordo com estratégica de busca elaborada, considerando número da patente, título, instituição depositante, inventores e data । depósito.

\begin{tabular}{|c|c|c|c|c|}
\hline Número Patente & Título & Instituição & Inventor & $\begin{array}{l}\text { Data de } \\
\text { Depósito }\end{array}$ \\
\hline $\begin{array}{c}\text { US2010310552- } \\
\text { A1 }\end{array}$ & $\begin{array}{l}\text { Producing antibody } \\
\text { by introducing non- } \\
\text { retroviral nucleic } \\
\text { acid into avian } \\
\text { embryo, incubating } \\
\text { embryo, growing } \\
\text { hatched chick, } \\
\text { obtaining offspring } \\
\text { and producing egg } \\
\text { white containing } \\
\text { antibody using } \\
\text { sexually mature } \\
\text { female offspring }\end{array}$ & $\begin{array}{c}\text { Rapp } \\
\text { J.C.(individual), } \\
\text { Christmann } \\
\text { L.(individual), } \\
\text { Leavitt } \\
\text { M.C.(individual) }\end{array}$ & $\begin{array}{c}\text { RAPP J C, } \\
\text { CHRISTMANN } \\
\text { L, LEAVITT M C }\end{array}$ & 21 Apr 2010 \\
\hline $\begin{array}{c}\text { US2007275390- } \\
\text { A1; } \\
\text { WO2007139546- } \\
\text { A3; } \\
\text { WO2007139546- } \\
\text { A2; }\end{array}$ & $\begin{array}{l}\text { Identifying an } \\
\text { animal having } \\
\text { desirable traits } \\
\text { comprises } \\
\text { determining the } \\
\text { presence of single } \\
\text { nucleotide } \\
\text { polymorphism in a } \\
\text { fatty acid binding } \\
\text { protein } 4 \text { gene }\end{array}$ & $\begin{array}{l}\text { Woodward B. e } \\
\text { Merial Ltd. }\end{array}$ & WOODWARD B & 25 Nov 2008 \\
\hline $\begin{array}{c}\text { US2007212713- } \\
\text { A1; } \\
\text { WO2007129219- } \\
\text { A2; } \\
\text { WO2007129219- } \\
\text { A3; }\end{array}$ & $\begin{array}{l}\text { Subgrouping animals } \\
\text { according to } \\
\text { genotype comprises } \\
\text { determining the } \\
\text { genotype of each } \\
\text { animal to be } \\
\text { subgrouped by } \\
\text { determining the } \\
\text { presence of single } \\
\text { nucleotide } \\
\text { polymorphisms of } \\
\text { interest in the GHR, } \\
\text { ghrelin, leptin, NPY } \\
\text { or UCP2 gene }\end{array}$ & $\begin{array}{c}\text { Moore S. } \\
\text { (individual), } \\
\text { Nkrumah D. J. } \\
\text { (individual), } \\
\text { Sherman E.L. } \\
\text { (individual) e } \\
\text { University of } \\
\text { Alberta }\end{array}$ & $\begin{array}{l}\text { MOORE S, } \\
\text { NKRUMAH D J, } \\
\text { SHERMAN E L, } \\
\text { NKRUMAH J D }\end{array}$ & $11 \mathrm{Jul} 2008$ \\
\hline
\end{tabular}


Tabela 2: Documentos patentários encontrados na base Derwent, de acordo com estratégica de busca elaborada, considerando número da patente, título, instituição depositante, inventores e data । depósito.

\begin{tabular}{|c|c|c|c|c|}
\hline Número Patente & Título & Instituição & Inventor & $\begin{array}{l}\text { Data de } \\
\text { Depósito }\end{array}$ \\
\hline $\begin{array}{c}\text { EP625007-A; } \\
\text { WO9314629-A; } \\
\text { WO9314629-A1; }\end{array}$ & $\begin{array}{l}\text { Gene transfer in } \\
\text { birds by } \\
\text { intramuscular } \\
\text { injection in ovo - to } \\
\text { increase growth rate, } \\
\text { feed efficiency or } \\
\text { give immune } \\
\text { response in poultry }\end{array}$ & $\begin{array}{l}\text { North Carolina } \\
\text { State University e } \\
\text { Embrex, Inc. }\end{array}$ & $\begin{array}{l}\text { PETITTE J M, } \\
\text { RICKS C A, } \\
\text { PETITTE J N, } \\
\text { SPENCE S E, } \\
\text { PETITE J M, } \\
\text { PETITTE J, } \\
\text { PHELPS P V, } \\
\text { WILLIAMS C }\end{array}$ & 12 Jun 1998 \\
\hline
\end{tabular}

Fonte: Autoria própria, 2012.

Observa-se que são universidades os maiores depositantes de pedidos de patentes, assim como possuem o maior número de publicações científicas. Além destas, inventores independentes e duas empresas privadas são titulares dos depósitos.

As proteções descritas nestes documentos se referem a métodos de sequenciamento e sequencia de genes detectando polimorfismos, principalmente visando à identificação de animais com características desejáveis. Estes métodos estão ligados a sistemas computacionais que são utilizados para gerenciar dados de SNP e outros dados relativos a animais específicos ou rebanhos.

Podemos verificar que as patentes mais significativas foram depositadas a partir de 2010 e apenas duas empresas privadas são cotitulares das patentes, indicando que o uso comercial é ainda restrito.

Quanto às empresas privadas cotitulares das patentes, podemos verificar que nenhuma tem seu foco de atuação em melhoramento genético de aves. Uma delas tem seu foco em soluções inovadoras em vacinas e sistemas de distribuição destas para sanidade animal e a outra é uma empresa que desenvolve soluções para a indústria avícola, especialmente de automação (como injeção em ovos) e biodispositivos para diagnósticos.

Das empresas focadas em genética de frangos de corte, verificamos que as três de relevância do mercado não apresentam tecnologias protegidas, nem publicações sobre o tema, segundo a estratégia de busca do presente trabalho. Verificou-se que estas empresas apresentam centros de pesquisa e desenvolvimento com investimento próprio em novas tecnologias e investem cerca de $10 \%$ do faturamento em P\&D, segundo informações divulgadas nos sites. Estes dados sugerem que a inovação é protegida por segredo industrial, visto ser uma área de concorrência extrema e qualquer melhoramento nas linhagens retorna ganhos significativos para a empresa.

Não foram encontradas informações relevantes de mercado quando se trata do uso destes genes comercialmente, ou seja, na obtenção de linhagens melhoradas. Entretanto, os métodos divulgados são utilizados como ferramentas para programas de melhoramento de frangos de corte, sendo uma tendência seu uso como marcador molecular na seleção. 
As publicações e patentes encontrados demonstram que os estudos são ainda de caráter básico na avicultura, tendo grandes oportunidades para o desenvolvimento de tecnologias inovadoras com aplicabilidade comercial.

\section{CONCLUSÃO}

Os resultados demonstram que o tema de biotecnologia avícola, focando em genes para a composição da carcaça em frango de corte, é recente, tendo poucos estudos a respeito. Apenas 64 documentos encontrados em publicações científicas foram pertinentes ao tema, sendo estas publicadas a partir de 1999. Dos sete documentos patentários relevantes, apenas um tem seu depósito em 1998, os demais a partir de 2008.

A China é o país com maior número de instituições e pesquisadores envolvidos no assunto, dominando a área de publicações científicas relativas ao tema. Quando de tecnologias com pedido de proteção, três documentos são chineses e outros três dos Estados Unidos, mostrando que estes países estão pesquisando métodos mais aplicados ao sistema produtivo.

Universidades e institutos de $\mathrm{P} \& \mathrm{D}$ são as organizações que apresentam mais estudos sobre o tema, com equipe maior e mais representatividade na área, não existindo informações de empresas privadas envolvidas nos estudos publicados.

As três empresas de melhoramento genético de frangos mais representativas não divulgam seus resultados, indicando que os mesmos são tratados com sigilo devido a grande competitividade que o setor apresenta.

Os estudos, em sua grande maioria, estão sendo conduzidos por universidades e instituições públicas de pesquisa, visando principalmente o desenvolvimento de métodos de sequenciamento e identificação de sequencias de genes importantes para determinadas características, direta e indiretamente ligadas ao rendimento de carcaça em frangos de corte, o que poderá colaborar com os estudos realizados na Embrapa Suínos e Aves e seus parceiros.

\section{PERSPECTIVAS}

De acordo com os documentos encontrados nas buscas, podemos verificar que o melhoramento genético utilizando genômica para seleção de frangos de corte via genes de composição para carcaça é um tema ainda incipiente e muito recente. As técnicas de biotecnologia têm sido incorporadas lentamente aos programas de melhoramento de frangos de corte, conforme ocorrido com a bovinocultura de corte, e possivelmente nos próximos anos, sejam utilizadas em larga escala com a seleção por marcadores moleculares.

Os resultados apontam oportunidades nesta área para a Embrapa Suínos e Aves e seus parceiros, que possuem uma linha de pesquisa sobre genes e sua influencia na composição de carcaças de frango de corte, sendo importante para o avanço do conhecimento a respeito do tema, principalmente com o uso prático dos dados publicados em artigos e documentos patentários.

Com a criação de um Laboratório Virtual da Embrapa no Exterior - Labex na China é importante a prospecção de instituições que possam ser parceiras da Embrapa neste país para aproximar pesquisadores, visando a colaboração nas pesquisas em biotecnologia em avicultura. 
Devido a forte concorrência é difícil a aproximação com as grandes empresas do setor de melhoramento avícola, entretanto, há grandes oportunidades para melhoramento de linhagens nacionais com foco em criação mais extensiva e para pequenas granjas, utilizando também seleção por marcadores moleculares, pela eficiência que traz aos programas de melhoramento animal.

Por fim, esta análise poderá auxiliar a Embrapa Suínos e Aves e seus parceiros no dimensionamento do rol de tecnologias protegidas a partir destas, além de facilitar o monitoramento de publicações científicas e do mercado tecnológico, uma vez que seguirá com a aquisição das informações de múltiplas fontes, de maneira rápida e eficiente, e pela sistematização dos dados encontrados, fortalecendo a análise de possibilidades, tendências e alternativas tecnológicas para a área de melhoramento de frangos de corte.

\section{REFERÊNCIAS}

ALBERS, G. A. A.; GROOT, A. Future trends in poultry breeding. World Poultry, 14:42-44, 1998.

ARGENTÃO, C. et al. Genetic and phenotypic parameters of growth and carcass traits of a male line of broilers raised in tropical conditions. In: CONGRESS ON GENETICS APPLIED TO LIVESTOCK PRODUCTION, 7., 2002, Montpellier. Proceedings... Castanet - Tolosan: Organizing committee WCGALP, v. 30, p. 333-336, 2002.

CAMPOS, E. J; PEREIRA, J. C. C. Melhoramento genético das aves. In: PEREIRA, J.C.C. Melhoramento genético aplicado à produção animal. Belo Horizonte: FEP-MVZ, cap. 17, p. 284-314, 1999.

CHAMBERS, J. R. Genetics of growth and meat production in chickens. In: CRAWFORD, R.D. Poultry breeding and genetics. Amsterdam: Elsevier Science, cap. 25, p. 614-631, 1990.

DEKKERS, J. C. M. Breeding in the 21th century: application of molecular technology. Proc. Assoc. Advmt. Anim. Breed. Genet. , v. 13, 1999. p. 1-16.

DEKKERS, J. C. M; HOSPITAL, F. The use of molecular genetics in the improvement of agricultural populations. Nature Reviews Genetics, v. 3, p. 22-32, 2002.

GAYA, L. G. Estudo genético da deposição de gordura abdominal e de características de desempenho, carcaça e composição corporal em linhagem macho de frangos de corte. 2003. 99f. Dissertação (Mestrado em Zootecnia) - Curso de Pós Graduação em Zootecnia, Faculdade de Zootecnia e Engenharia de Alimentos da Universidade de São Paulo. São Paulo, 2003.

GAYA, L. G.; MOURÃO, G.B.; FERRAZ, J.B.S. Aspectos genético-quantitativos de características de desempenho, carcaça e composição corporal de frangos. Cienc. Rural. v.36, p. 709-716, 2006.

LEDUR, M. C., BERTANI, G. R., NONES, K. Genômica nos Programas de Melhoramento Genético Avícola. APINCO 2003, Conferência de Ciência e Tecnologia Avícolas, Anais... 7 a 9 de Maio de 2003. Campinas, SP, 2003. p. 87-105.

WANG, L. et al. Genetic correlations among growth, feed and carcass traits of broiler sire and dam populations. Poultry Science, Savoy, v. 70, 1991. p. 719-725. 